\title{
A multidisciplinary approach to the investigation of "La Caverna dell'Antimateria" (1958-1959) by Pinot Gallizio
}

\author{
Giovanni Bartolozzi ${ }^{1}$, Costanza Cucci ${ }^{1}$, Veronica Marchiafava ${ }^{1 *}$, Susanna Masi ${ }^{2}$, Marcello Picollo ${ }^{1}$, Emanuela Grifoni ${ }^{3}$, \\ Stefano Legnaioli ${ }^{3}$, Giulia Lorenzetti ${ }^{3}$, Stefano Pagnotta ${ }^{3}$, Vincenzo Palleschi ${ }^{3}$, Francesca Di Girolamo ${ }^{4}$, \\ Jacopo La Nasa ${ }^{4}$, Francesca Modugno ${ }^{4}$ and Maria Perla Colombini ${ }^{4}$
}

\begin{abstract}
Background: This study concerns the application of non-invasive and micro-invasive analyses for the study of a contemporary artwork entitled La Caverna dell'Antimateria ("The Cave of Antimatter") which was created by Pinot Gallizio in 1958-1959. The work represents one of the most significant examples of industrial painting. It consists of a total of 145 meters of painted canvas, designed in order to cover the entire floor plan of the René Drouin gallery in Paris, where it was displayed for the first time. Gallizio wanted to create an environment in which visitors could find themselves immersed in painting, in what he termed as a "work-environment".

Non-invasive (Fibre Optic Reflectance Spectroscopy) and micro-invasive analyses (Fourier Transform Infrared and micro-Raman Spectroscopies, Pyrolysis-Gas Chromatography and Gas Chromatography/Mass Spectrometry) were performed on three of the canvases which constitute this work of art in order to obtain information regarding the artistic materials used by Gallizio.
\end{abstract}

Results: Pigments and unconventional materials (such as metal wires, sand) are present in the canvases that form the ceiling. The colours are unevenly distributed on the surface, thus revealing large areas of the white preparation below. In the canvas of the wall, instead, the paint is applied more uniformly and gives a dark colour cast. The analytical results led to the identification of many of the materials used by Gallizio. The pictorial palette consists of both inorganic and organic pigments, while polyvinylacetate, pure or mixed with a siccative oil, was identified as a binder thus confirming what was reported by the artist in his notes.

Conclusions: The results of this research provide information concerning the artistic technique used by Pinot Gallizio. The analyses were successfully performed both in situ and on micro-samples in order to characterise the pigments of the coloured area, the ground layer and the organic binders.

Keywords: Non-invasive analysis, Micro-invasive analysis, FORS, FT-IR, Micro-Raman, Py-GC/MS, GC-MS, Contemporary art

\section{Introduction}

Giuseppe (Pinot) Gallizio (Alba, 1902-1964) was the main exponent of the Italian industrial painting movement. He developed the concept of industrial painting at the end of the 1950s, abandoning the limited format of traditional paintings for the virtually one of unlimited rolls of canvas. His works had neither a predetermined direction nor a

\footnotetext{
* Correspondence: v.marchiafava@ifac.cnr.it

"Nello Carrara" Institute of Applied Physics - National Research Council (IFAC-CNR), Via Madonna del Piano 10, Sesto Fiorentino, FI 59100, Italy Full list of author information is available at the end of the article
}

unique point of view. One of the main features of this new concept of art was that of cutting and selling paintings by the meter, according to the size required by the buyer in order to inflate the market and make art available to everyone.

In 1958, the writers Guy Debord and Michèle Bernstein, who were friends of Gallizio and co-founders of the "International Situationist", invited Gallizio in person to give an exhibition at the "Galerie René Drouin" in Paris. The project was to cover the entire gallery space (from floor to ceiling) - the white walls which were normally adorned 
with paintings - with about 150 meters of industrial painting, thus converting the gallery into a synesthetic environment. It was for this project that Gallizio created, in 1958-59, La Caverna dell'Antimateria ("The Cave of Antimatter"; inventory number: 58 DT 38) as a "workenvironment" that provided a concrete representation of the theory of the Anti-World and gave a voice to the new concept of matter as advanced by contemporary physics [1]. The work consisted of nine painted canvases that served to cover the ceiling, walls and floor, and six painted curtains to screen the front door and the staircase on the left wall. All the canvases were painted with different colours that were mixed and/or overlaid with each other. As reported in his Diario-Registro ("Diary-Register"), Gallizio used several pictorial techniques: "olio tradizionale" ("traditional oil"), "soffitto [...] resine soffiate a polvere, graffite ad umido" ("ceiling [...]: powder-blown resins, wet-painted engraved"), "pavimenti - tela di lino preparata con vinavil [...] tecnica delle aniline alla nitro" ("floors: linen canvas prepared with vinavil [...] nitro aniline technique"), "tecnica a fuoco, le grandi sacche vengono intaccate con ferro rovente e soffiate - si rompono le sacche con effetti grandi" ("Fire technique: the large bags are burned with a red-hot iron tool and then blown up - the bags break with great effects"). According to the testimony of his son, Giorgio Gallizio, in fact, the canvases for the ceiling were made on the roof of the "Experimental Laboratory of Alba" (where Pinot Gallizio created his works). On that occasion, the artist sewed bags containing pigments and firecrackers, and these were blown up in order to randomly sprinkle colours on canvases that had previously been prepared with Vinavil ${ }^{\circ}$ glue $[2,3]$.

Today the work, which consists of only seven canvases (all five canvases for the walls and two for the ceiling), is currently stored in the warehouses of the "Luigi Pecci Centre for Contemporary Art" (Prato, Italy). Each canvas is rolled up on cylindrical supports.

Although the artwork is in a good state of conservation, a diagnostic survey was performed to recognise the materials used by the artist, in order to identify the most appropriate preventive conservation treatments. For this purpose, non-invasive and micro-invasive analyses were carried out. Specifically, thanks to the courtesy of the curators of the museum, it was possible to have access to three canvases (two of the ceiling and one of the wall). These were unrolled and then analysed using a non-invasive in situ technique (Fibre Optic Reflectance Spectroscopy, FORS in the $350-2200 \mathrm{~nm}$ range) on 107 spots (2-mm-in-diameter). The canvases were also sampled after FORS measurements and the samples were then analysed in the laboratories by means of Fourier Transform Infrared (FT-IR), FORS (in the 270-800 nm range), and micro-Raman spectroscopies. Pyrolisis-Gas Chromatography/Mass Spectrometry (Py-GC/MS) and
Gas Chromatography/Mass Spectrometry (GC/MS) were also performed on three samples.

The present study is part of the more extensive 2years CoPAC (Preventive Conservation of Contemporary Art) research project, which focused on the analysis of contemporary artists' materials and artistic techniques by studying a set of selected contemporary artworks belonging to Tuscan museums and institutions.

\section{Materials and methods \\ Samples}

The three unrolled canvases, the objects of the diagnostic survey, are reported in Figure 1. According to the curators of the museum, canvas $\mathrm{L}$ constitutes one of the walls of La caverna dell'Antimateria, while canvas P and canvas A are from the ceiling.

Eighteen micro samples were collected from canvas L, 13 from canvas $\mathrm{P}$ and 20 from canvas $\mathrm{A}$ (cited in the text as L1-L18, P1-P13 and A1-A20, respectively).

\section{Fibre optic reflectance spectroscopy}

FORS measurements were acquired both in situ on different areas of the three canvases and in laboratory on almost all the samples collected to evaluate eventual differences of the inner surface with respect to the external one and to extend the study to the UV range.

FORS spectra in the UV-vis-NIR range (350-2200 nm) were acquired by using two single-beam Zeiss spectroanalysers, model MC601 (190-1015 nm range) and model MC611 NIR 2.2WR (910-2200 nm range), which were housed together in a compact and portable chassis for in situ analyses. The data acquisition step was $0.8 \mathrm{~nm} /$ pixel for the 1024-element silicon photodiode array detector (MCS601), and $6.0 \mathrm{~nm} /$ pixel for the 256-element InGaAs diode array detector (MCS611 NIR 2.2 WR). The radiation between $320 \mathrm{~nm}$ and $2700 \mathrm{~nm}$, which was provided by a voltage-stabilized $20 \mathrm{~W}$ halogen lamp (mod. CLH600), was conveyed to the sample by means of a quartz optical fibre bundle that also transported the reflected radiation to the detectors. The geometry of the probe head was $8^{\circ} / 8^{\circ}$.

A Zeiss spectrum analyser, model CLX 500, equipped with a xenon lamp was used to investigate the 270$800 \mathrm{~nm}$ (UV-vis) range.

Calibration was performed by means of a $99 \%$ Spectra$l^{\circ}{ }^{\circ}$ diffuse reflectance standard. Spectra were processed using Aspect Plus ${ }^{\circ} 1.80$ software.

\section{Fourier transform infrared spectroscopy}

Transmittance spectra on the samples dispersed in $\mathrm{KBr}$ pellets were collected by means of a Nicolet spectrophotometer, model Nexus 470 E.S.P. ${ }^{\mathrm{m}}$, equipped with a $\mathrm{SiC}$ Globar and a DTGS detector. The IR spectra were 


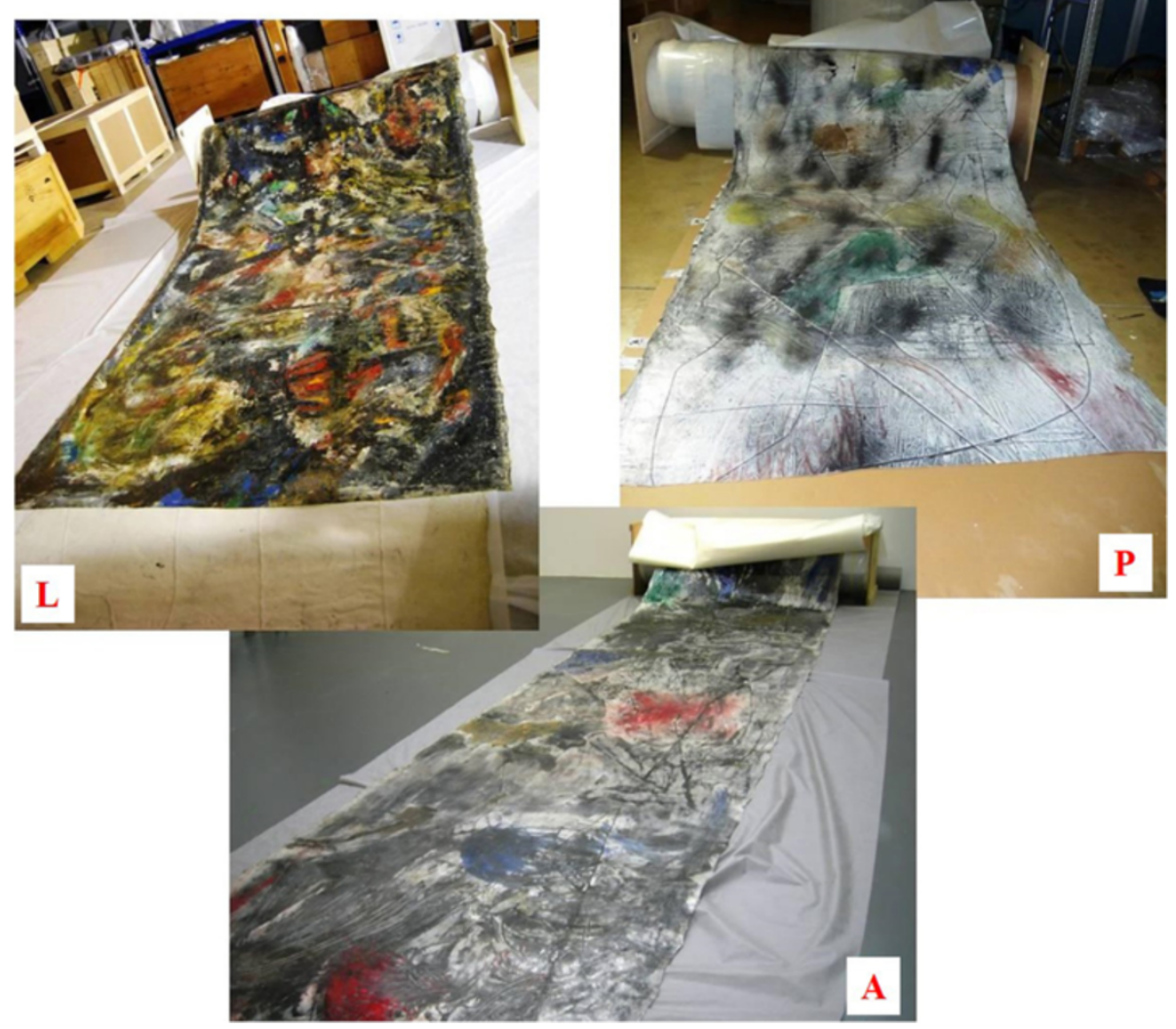

Figure 1 La Caverna dell'Antimateria: canvas of the wall (L) and canvases of the ceiling (P, A).

acquired in the $4000-400 \mathrm{~cm}^{-1}$ range (64 scans were acquired using a $4 \mathrm{~cm}^{-1}$ resolution).

ATR spectra were recorded using a Perkin-Elmer System 2000 spectrometer equipped with a Golden Gate accessory. 32 scans were acquired on each sample in the $4000-600 \mathrm{~cm}^{-1}$ spectral range using a $2 \mathrm{~cm}^{-1}$ resolution.

\section{Micro-raman spectroscopy}

The micro-Raman analysis were carried out using a Renishaw Raman Invia instrument. This instrument is equipped with a 1800 grooves $/ \mathrm{mm}$ diffraction grating, a CCD detector, and a 50X magnifying lens. The Raman spectra were acquired using a HeNe laser $(\lambda=633 \mathrm{~nm})$ as radiation source.

\section{Pyrolysis-gas chromatography/mass spectrometry}

Analyses were performed using a pyrolyser (CDS Pyroprobe 5000 series) coupled with a GC/MS system consisting of a $6890 \mathrm{~N}$ Gas Chromatography System combined with a 5973 Mass Selective single quadrupole mass spectrometer (Agilent Technologies, Palo Alto, CA, USA). Each sample $(\sim 0.2 \mathrm{mg})$ was placed on glass wool inside a quartz tube, and then inserted into the coil of the resistively-heated Pt filament of the pyrolyser. Pyrolysis conditions: initial temperature $50^{\circ} \mathrm{C}, 20^{\circ} \mathrm{C} / \mathrm{ms}$ up to final temperature $\left(600^{\circ} \mathrm{C}\right.$ for Laropal A81 and Regalrez 1094; $500^{\circ} \mathrm{C}$ for $\mathrm{MS} 2 \mathrm{~A}$ ), final temperature lasting for $10 \mathrm{sec}-$ onds. The pyrolyser interface was kept at $130^{\circ} \mathrm{C}$, the transfer line at $300^{\circ} \mathrm{C}$ and the valve oven at $290^{\circ} \mathrm{C}$; the split ratio was 1:10. Chromatographic separation of analytes was performed with a fused silica capillary column HP-5MS (J\&W Scientific, Agilent Technologies, 5\% diphenyl-95\% dimethyl-polysiloxane, $30 \mathrm{~m} \times 0.25 \mathrm{~mm}$ i.d., $0.25 \mu \mathrm{m}$ film thickness), preceded by $2 \mathrm{~m}$ of deactivated fused silica pre-column that had an internal diameter $0.32 \mathrm{~mm}$. Chromatographic conditions: $40^{\circ} \mathrm{C}$ for $5 \mathrm{~min}, 10^{\circ} \mathrm{C} / \mathrm{min}$ up to $300^{\circ} \mathrm{C}, 300^{\circ} \mathrm{C}$ for $10 \mathrm{~min}$. The helium gas flow was set at the constant flow mode $1.3 \mathrm{~mL} /$ $\min$ (purity 99.9995\%) [4].

\section{Gas chromatography/mass spectrometry}

For the GC/MS analyses, a portion of sample $(0.5 \mathrm{mg})$ was subjected to saponification assisted by microwaves in $300 \mu \mathrm{L}$ of $\mathrm{KOH}$ in $\mathrm{ETOH} 10 \%$ wt at $80^{\circ} \mathrm{C}$ for $60 \mathrm{~min}$. The solution was acidified with hydrochloric acid $(6 \mathrm{M})$ and then extracted with diethyl ether $(200 \mu \mathrm{L}$, three times). The extract was evaporated to dryness under nitrogen stream and then subjected to derivatisation with 
$20 \mu \mathrm{L}$ of N,O-bis(trimethylsilyl)trifluoroacetamide (BSTFA), $200 \mu \mathrm{L}$ of isooctane and $5 \mu \mathrm{L}$ of tridecanoic acid solution at $60^{\circ} \mathrm{C}$ for $30 \mathrm{~min} .5 \mu \mathrm{L}$ of hexadecane solution were added just before injection.

The GC/MS instrumentation consisted of a Trace GC 2000 chromatographic system equipped with a PTV injection port and coupled to an ITQ 900 ion trap (Thermo Quest, US).

Samples were injected in split-less mode at $280^{\circ} \mathrm{C}$. GC separation was performed on a fused silica capillary column HP-5MS (J\&W Scientific, Agilent Technologies, US, stationary phase $5 \%$ diphenyl-95\% dimethylpolysiloxane, $30 \mathrm{~m}, 0.25 \mathrm{~mm}$ i.d., $0.25 \mu \mathrm{m}$ film thickness). Chromatographic conditions: initial temperature $80^{\circ} \mathrm{C}$, $2 \mathrm{~min}$ isothermal, $10^{\circ} \mathrm{C} / \mathrm{min}$ up to $200^{\circ} \mathrm{C}$, 4 min isothermal, $6^{\circ} \mathrm{C} / \mathrm{min}$ up to $280^{\circ} \mathrm{C}, 40$ minutes isothermal. The helium (purity 99.9995\%) gas flow was set in constant flow mode at $1.2 \mathrm{~mL} / \mathrm{min}$. MS parameters: electron impact ionization (EI, $70 \mathrm{eV}$ ) in positive mode; ion source temperature $230^{\circ} \mathrm{C}$; scan range $50-700 \mathrm{~m} / \mathrm{z}$; interface temperature $280^{\circ} \mathrm{C}$. Peak assignment was based on a comparison with library mass spectra (NIST 1.7, WILEY275).

\section{Results and discussion}

The three canvases under investigation appeared to be in a good state of conservation, although several craquelures were identified. These were probably due to the mode of storage. It is possible, in fact, that fewer craquelures would have been found if the canvases had been stored stretched, instead of being rolled up.

In looking at the three selected stripes, a remarkable difference in the execution technique was noted. This was due to the different location inside the cave and to the different significance of each canvas. Many unconventional materials were detected in the canvases belonging to the ceiling: wires, sand, and a probable residue of gunpowder used to 'shoot' the colour onto the fresh binder. The colours were unevenly distributed on the surface, leaving large areas of the white preparation below to shine through. Instead, no unconventional materials were found in the stripe of the wall and the paint was applied more evenly, resulting in a visibly darker colour cast.

The study of the data acquired in situ and on the samples made it possible to identify most of the materials used by the artist. In particular, considering the binder, the FT-IR spectra of the majority of the analysed samples showed, in more or less evident way, the typical absorption bands of a polyvinylacetate resin (PVAc): 2921 and $2852 \mathrm{~cm}^{-1}$ (aliphatic $\mathrm{CH}$ stretching), $1735 \mathrm{~cm}^{-1}(\mathrm{C}=\mathrm{O}$ stretching), $1427 \mathrm{~cm}^{-1}$ (asymmetric $\mathrm{CH}_{2}$ bending), $1375 \mathrm{~cm}^{-1}$ (asymmetric $\mathrm{CH}_{3}$ bending), $1240 \mathrm{~cm}^{-1}$ ( $\mathrm{CH}$ in plane bending), $1125 \mathrm{~cm}^{-1}$ (C-O stretching) [5].

Py-GC/MS and GC/MS analyses were performed on different samples in order to confirm the chemical composition of the medium used by the artist.

- the pyrolitic profiles of samples L3, L5 and L12 showed the presence of several markers of a polyvinylacetate resin, such as benzene, acetic acid and different aromatic derivatives [6]. The chromatogram also showed the presence of characteristic markers of a drying oil, with large amount of palmitic, oleic and stearic acids (Figure 2). In order to confirm the presence of a siccative oil, GC/MS analyses after saponification, extraction and derivatisation with a silanising agent,

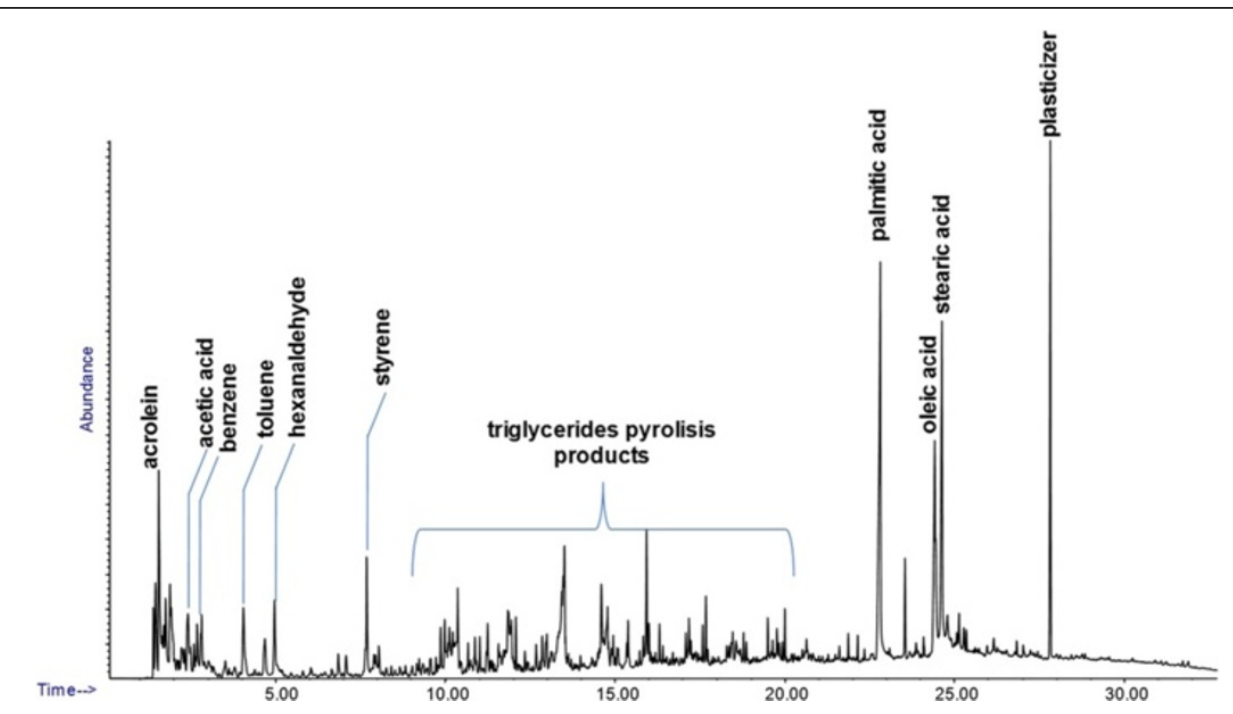

Figure 2 Py-GC/MS chromatogram of sample L12. 
Table $1 \mathrm{GC} / \mathrm{MS}$ analysis results for sample L3, L5 and L12

\begin{tabular}{llll}
\hline Parameters & \multicolumn{2}{l}{ Sample } & \\
\cline { 2 - 4 } & L3 & L5 & L12 \\
\hline P/S & 0.8 & 1.2 & 1.2 \\
A/P & 3.1 & 2.6 & 1.2 \\
O/S & 0.2 & 0.3 & 0.9 \\
$\mathbf{\Sigma}$ Dic $_{\%}$ & 24.4 & 34.5 & 26.6
\end{tabular}

Legend - P: palmitic acid, S: stearic acid, A: azelaic acid, O: oleic acid; $\Sigma D^{2} \mathrm{C}_{\%}$ : total amount of dicarboxylic acids (\%).

were performed. The results can be seen in Table 1, and the chromatogram of sample L12 is shown in Figure 3. The GC/MS analysis shows the presence of all the main fatty acids characteristic of an aged oil, such as suberic, azelaic and sebacic acids, and also common dicarboxylic acids deriving from the drying process of a siccative oil [7].

- the pyrolitic profiles of samples A2 and A19 (Figure 4) showed only the presence of the characteristic molecular markers of a PVAc resin and large amounts of various plasticisers, characteristic additives used in the production of synthetic polymers; no markers of any oil were identified.

- as for samples A2 and A19, the pyrolitic profile of sample P8 showed only the presence of markers deriving from the pyrolysis of a PVAc resin.

These results are in agreement with the notes made by Gallizio himself, who, in his Diario-Registro, declared that he used Vinavil ${ }^{\circ}$ and/or traditional siccative oils as binding media $[1,3,8]$.
The study of the coloured areas made it possible to affirm that Gallizio did not seem to have any specific preferences in his 'artistic materials', since he used both inorganic and organic pigments for the creation of this work.

In considering the FT-IR spectra of the white samples, we were able to identify absorption bands of barium sulphate at $\mathrm{ca}$. 1166, 1111, $1067\left(\mathrm{SO}_{4}{ }^{2-}\right.$ asymmetric stretching), $983\left(v_{1} \mathrm{SO}_{4}{ }^{2-}\right.$ in plane bending), 631 and $604 \mathrm{~cm}^{-1}$ (doublet, $v_{4} \mathrm{SO}_{4}{ }^{2-}$ out of plane bending) [9]. In addition, FORS spectra showed two absorption bands at $670 \mathrm{~nm}$ and $728 \mathrm{~nm}$, which are typical of $\mathrm{Co}^{2+}$ ion in pseudo-tetrahedral coordination as a vicariant of $\mathrm{Zn}^{2+}$ in the structure of $\mathrm{ZnS}$. The presence of this ion has been associated with a lithopone pigment $\left(\mathrm{BaSO}_{4}+\mathrm{ZnS}\right)$ produced after the mid-1920s [10,11]. The presence of $\mathrm{ZnS}$ in these samples was confirmed by their FORS spectrum in the 270-800 $\mathrm{nm}$ range. The typical strong absorption in the UV region below $350 \mathrm{~nm}$ with an inflection point at $340 \mathrm{~nm}$ ascribable to $\mathrm{ZnS}$ electronic transition was also observed [12] (Figure 5).

Micro-Raman analysis of white pigments confirmed the outcomes of both FT-IR and FORS. In most cases, a lithopone pigment was indeed identified, while in some samples, only the most intense peak of barium sulphate at $988 \mathrm{~cm}^{-1}$, due to the sulphate stretching mode $\left(v_{1}\right)$, was detected (Figure 6A and B) [13].

It was not possible to identify the black pigment by means of FT-IR and FORS analyses. However, Raman spectra revealed the characteristic bands of $\mathrm{C}-\mathrm{C}$ bonds (Figure 7), which are related to the presence of a carbon-based pigment $[14,15]$.

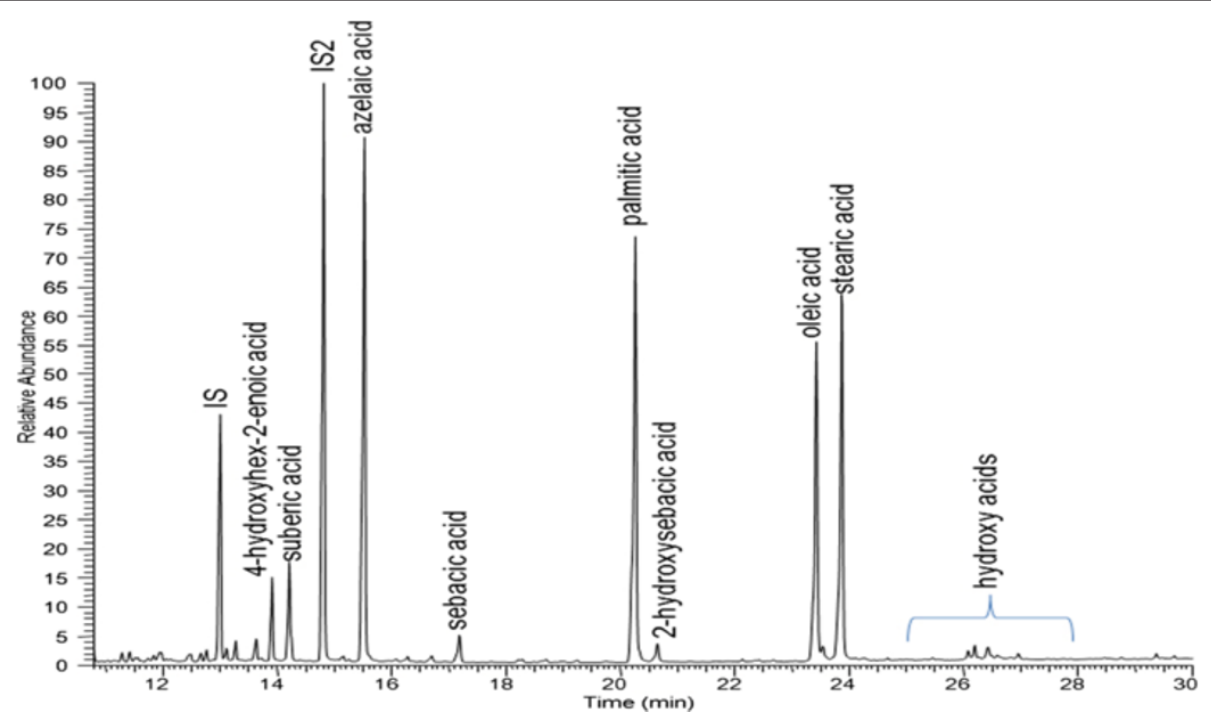

Figure 3 GC/MS chromatogram of sample L12. It was obtained after saponification, extraction and derivatization; IS1: hexadecane, IS2: tridecanoic acid. 


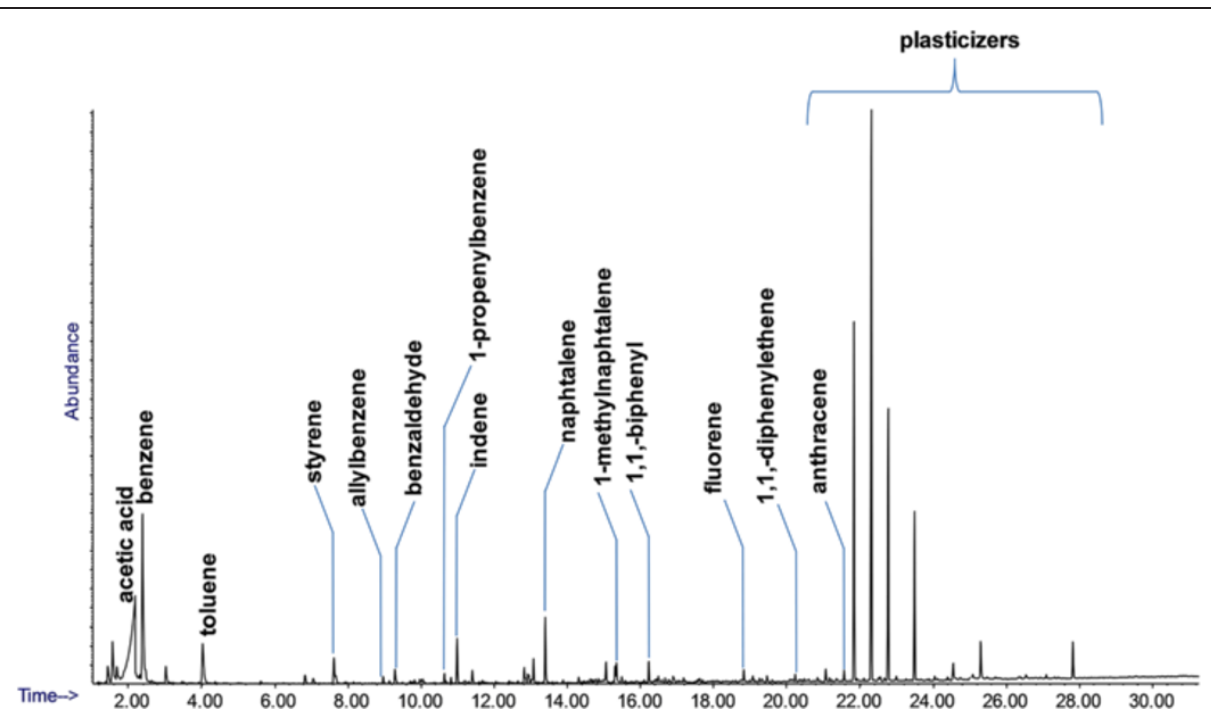

Figure 4 Py-GC/MS chromatogram of sample A19. It shows the typical markers of PVAc resin.

Two different pigments were identified on the blue areas. In considering FT-IR spectra of the blue samples detached from the ceiling, we were able to identify absorption bands of ultramarine blue. In particular, overlapping stretching bands of $\mathrm{Si}-\mathrm{O}-\mathrm{Si}$ and $\mathrm{Si}-\mathrm{O}-\mathrm{Al}$ between $1150 \mathrm{~cm}^{-1}$ and $950 \mathrm{~cm}^{-1}$ were present, as well as bands at 700 and $650 \mathrm{~cm}^{-1}$, which were due to $\mathrm{Si}-\mathrm{O}$ bond vibrations (Figure 8) [16-18].
Ultramarine blue was also identified in the Raman spectra in Figure 9, where its characteristic peaks (the symmetric stretching vibration $\left(v_{1}\right)$ of $S_{3}^{-}$at $548 \mathrm{~cm}^{-1}$ and the first overtone of the stretching vibration $\left(1 v_{1}\right)$ at $1096 \mathrm{~cm}^{-1}$ ) are clearly visible $[19,20]$.

Furthermore, the UV-vis-NIR reflectance spectra showed a maximum of reflectance at about $447 \mathrm{~nm}$ and one around $770 \mathrm{~nm}$, thus confirming the reddish

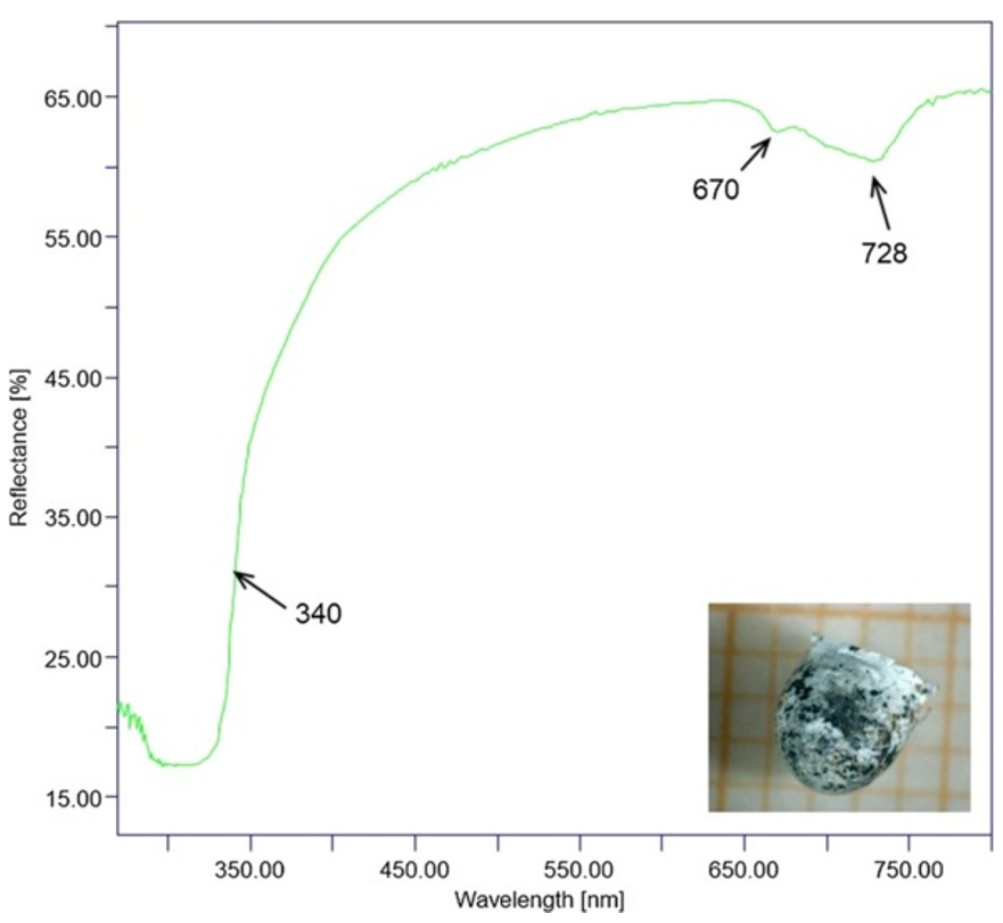

Figure 5 FORS spectrum of sample P3 in the $\mathbf{2 7 0 - 8 0 0 ~} \mathrm{nm}$ spectral range. It shows the spectral features of the lithopone pigment. 

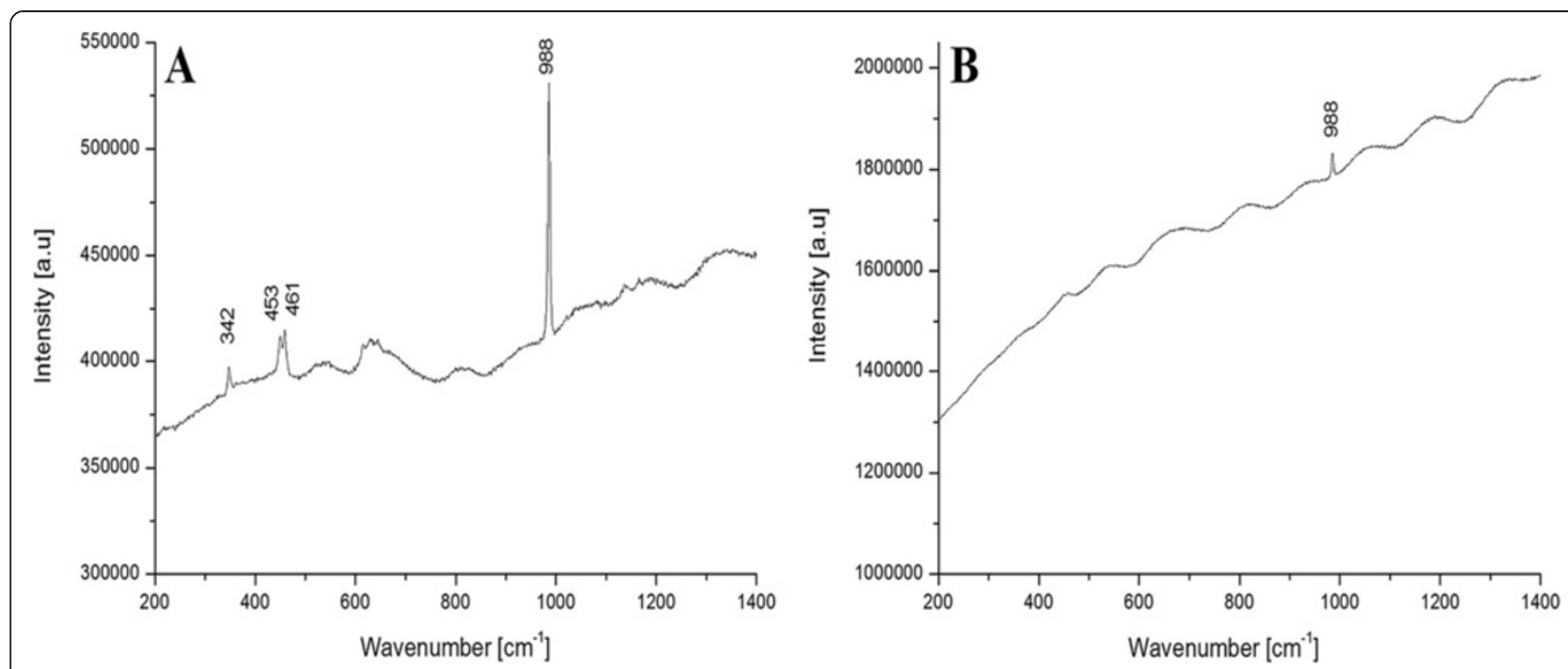

Figure 6 Raman spectrum of sample P3 (A) and L2 (B). The former shows the absorption bands of lithopone, the latter only the most intense absorption due to barium sulphate.

component in the hue of this blue pigment as reported in the literature [21]. The absorption centred at $600 \mathrm{~nm}$ was due to a charge transfer electronic transition that was related to the presence of the $S_{3}{ }^{-}$ion in the crystal structure of the aluminosilicate [22].

A phthalocyanine blue pigment was identified on the canvas of the wall. Indeed, as can be seen in Figure 10, the Raman spectrum of sample L13 shows the characteristic peaks of the phthalocyanine blue (PB15), whose Raman signals are very intense in the $1342-1328 \mathrm{~cm}^{-1}, 1530-1518$ $\mathrm{cm}^{-1}, 681-679 \mathrm{~cm}^{-1}$, and $745-748 \mathrm{~cm}^{-1}$ ranges $[14,15,23]$.
Red areas were also created by using different pigments. In considering FORS spectra acquired in situ, for example, spectra with the typical spectral features of iron oxides (Figure 11A) as well as spectra with an "S"shape absorption band and an inflection point at $600 \mathrm{~nm}$ (Figure 11B) were acquired.

In the latter case, only the Raman analysis of the red sample A14 enabled us to make an unequivocal identification of the pigment responsible for the colour. The Raman absorptions at 1620, 1560, 1499, 1447, 1397, 1334, 1258, 1221, 1187, 1131, 1080, 990, 845, 799, 726,

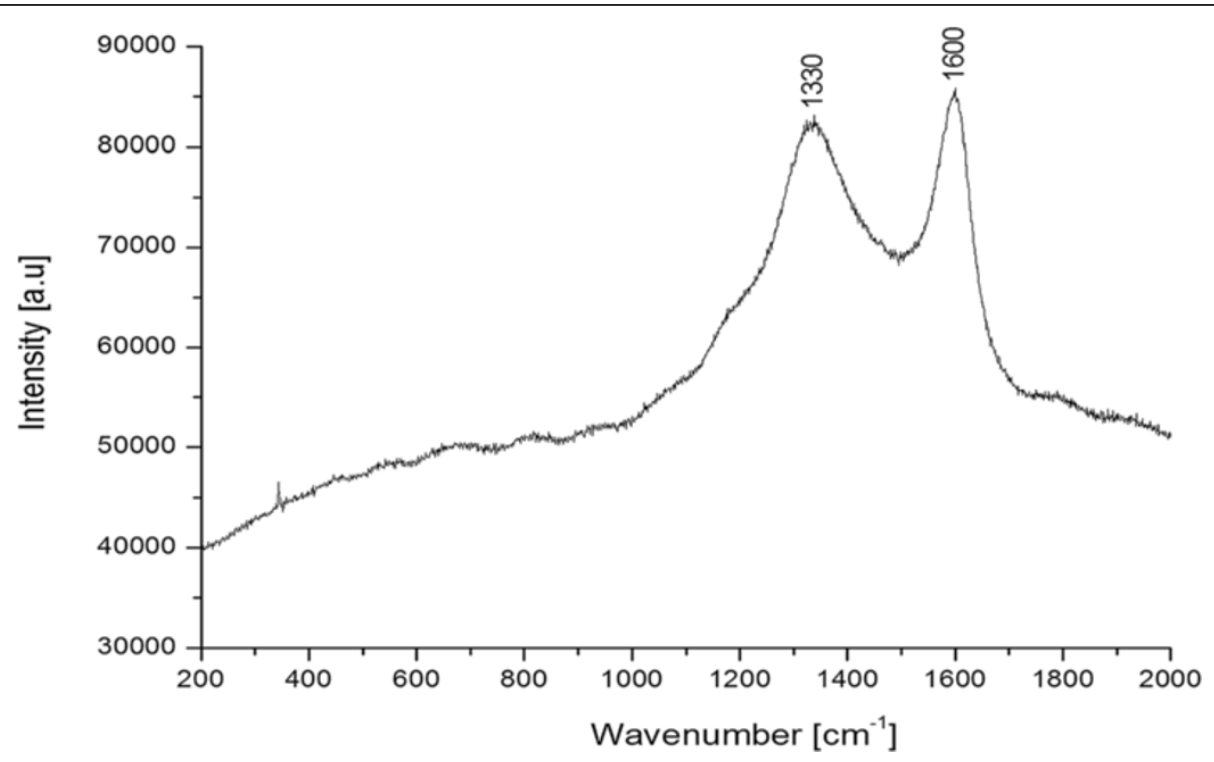

Figure 7 Raman spectrum of sample L5. It shows the typical features of an amorphous carbon based pigment. 


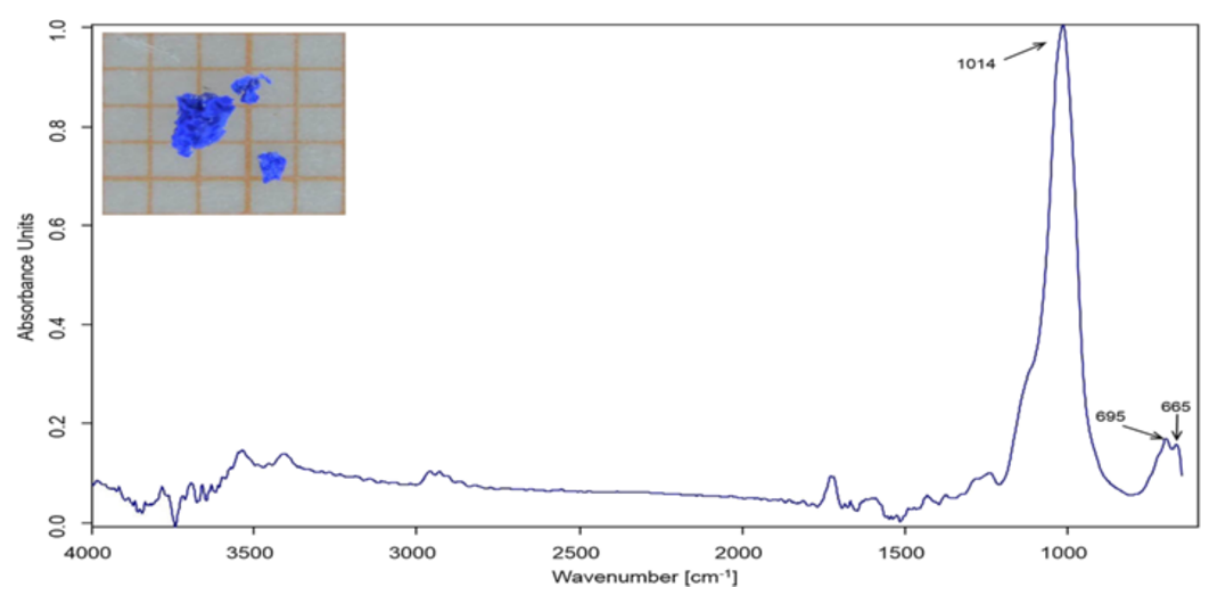

Figure 8 ATR FT-IR spectrum of sample A3 (inner surface). It shows the absorption bands of the ultramarine pigment.

620, 459, 386 and $344 \mathrm{~cm}^{-1}$ were, in fact, attributable to a PR3 monoazo pigment [23,24].

Gallizio used different pigments also for the yellow colours. The FORS spectra acquired in situ on different yellow areas showed different spectral features. The brilliant yellow of canvas A, for example, had an "S"-shape spectrum with an inflection point at $486 \mathrm{~nm}$ and an intense absorption band in the UV-vis region, due to a $n(\mathrm{azo}) \rightarrow \pi^{*}$ transition of a monoazo PY3 yellow pigment [25].

Also the "S"-shape spectrum of the dark yellow had an intense absorption band in the UV-vis region. In this case, however, the first derivative spectrum showed an intense maximum at $534 \mathrm{~nm}$ with a weak shoulder at $486 \mathrm{~nm}$. These spectral features were possibly due to the presence of a mixture of a lead chromate yellow with a monoazo PY3 pigment $[22,25]$. This hypothesis was confirmed by the Raman spectrum of sample L14 in which the bands of lead chromate (355 and $840 \mathrm{~cm}^{-1}$ ), of calcite (451 and $988 \mathrm{~cm}^{-1}$ ) and of monoazo PY3 pigment (412, 622, 649, 747, 1035, 1140, 1188, 1275, 1310, 1338, 1387, 1566, 1600, 1615 and $1670 \mathrm{~cm}^{-1}$ ) were easily detectable.

In the case of the yellow ochre, the FORS spectrum showed the absorption of a white pigment (at $364 \mathrm{~nm}$ ) together with the absorption bands of goethite, $\alpha-\mathrm{FeOOH}$. In fact, charge transfer transition absorption at $480 \mathrm{~nm}$, as well as ligand field transition absorptions at 650 and $920 \mathrm{~nm}$ were found [26,27].

In the FT-IR spectrum of sample A8 (Figure 12), the absorption bands at 3121, 898 and $797 \mathrm{~cm}^{-1}$ unequivocally

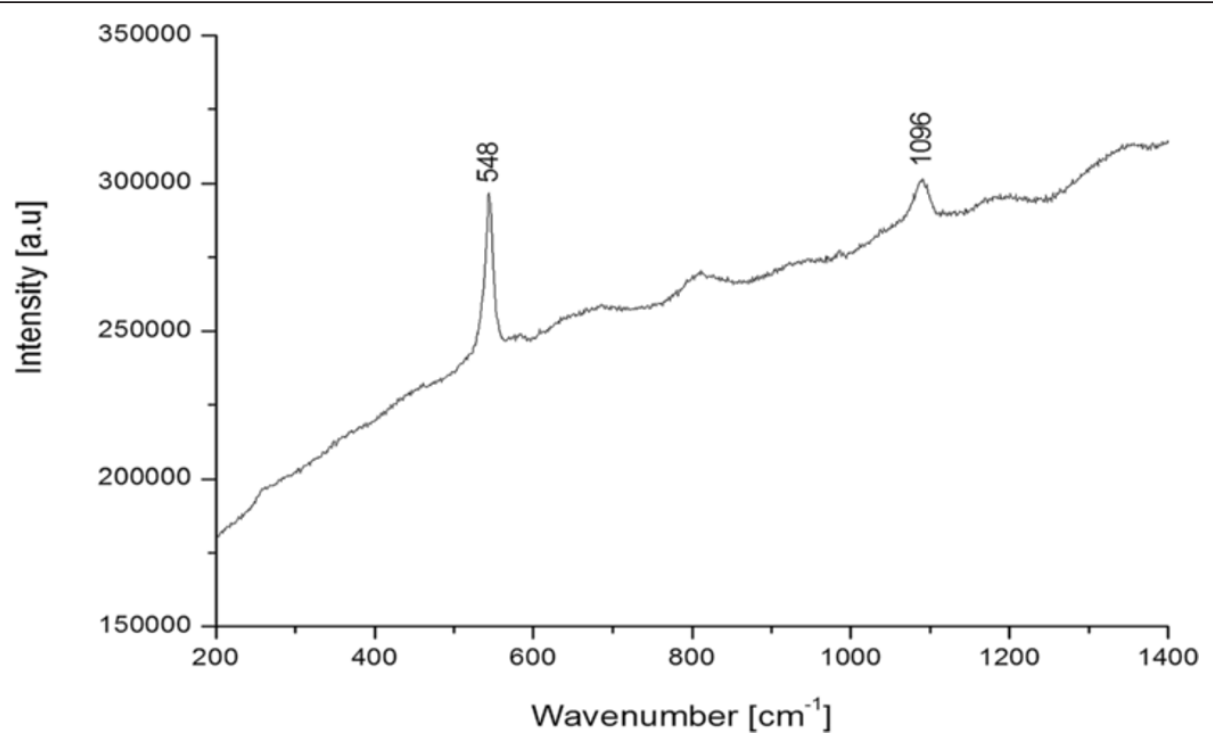

Figure 9 Raman spectrum of sample P4. It shows the spectral features of the ultramarine pigment. 


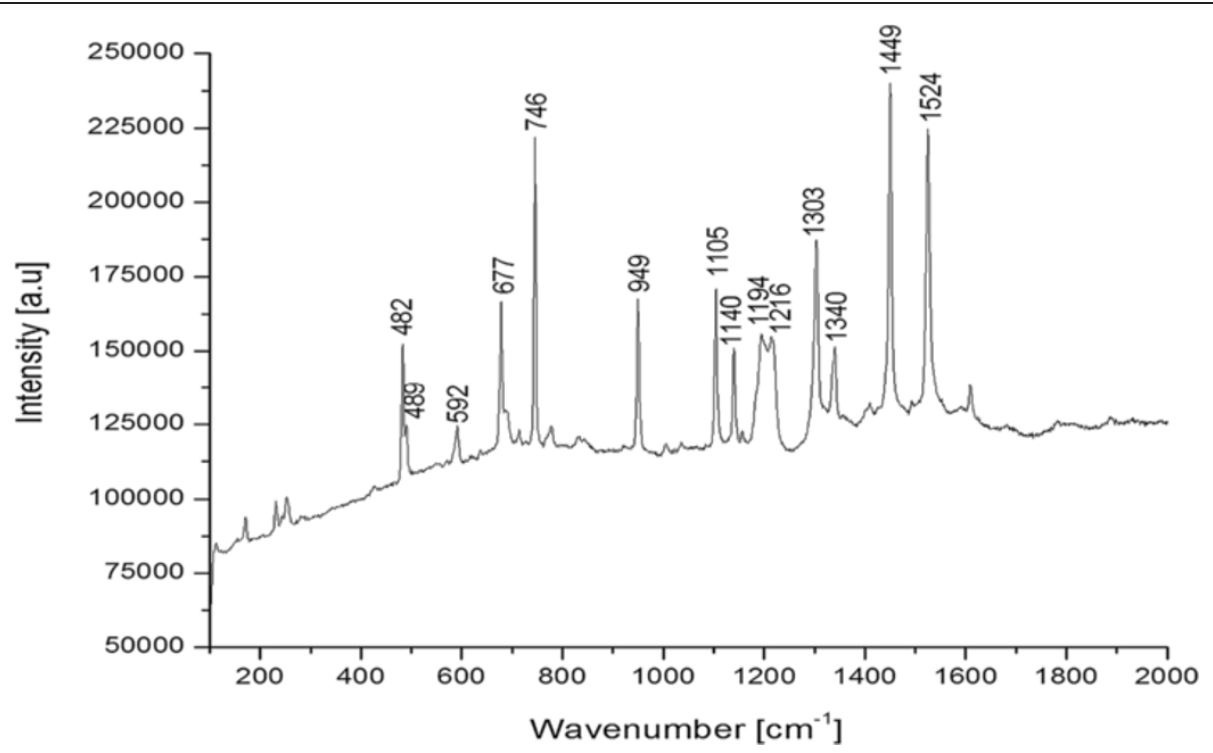

Figure 10 Raman spectrum of sample L13. It shows the spectral features of a phthalocyanine blue (PB15) pigment.

confirmed the presence of goethite in the yellow ochre areas $[28,29]$.

Lastly, the green areas were created by mixing a blue pigment with a yellow one. FORS analysis (Figure 13) enabled us to hypothesise the presence of a yellow monoazo pigment (absorption under $480 \mathrm{~nm}$ ) together with a phthalocyanine blue (absorptions at $620 \mathrm{~nm}$ and $697 \mathrm{~nm})[30,31]$.

In considering FT-IR spectra of samples L17 and L18, instead, we could identify only the absorption bands due to the binder and to the $\mathrm{BaSO}_{4}$. Thus, no useful information on the coloured compounds was obtained. The proof that a blue-yellow mixture was used for the green areas was obtained from the Raman analyses. Raman spectra of green samples, in fact, showed both the absorptions of a phthalo blue PB15 pigment at 1530, 1450, 1139, 1106, 745 and $680 \mathrm{~cm}^{-1} 5$ and the peaks due to a monoazo PY3 pigment at 1613, 1543, 1494, 1425, 1385, $1337,1310,1189,795,395$ and $142 \mathrm{~cm}^{-1}[23,24]$.

\section{Conclusion}

This research was focused on the application of spectroscopic and cromatographic techniques to the study of some of the materials used in the La caverna dell'Antimateria.

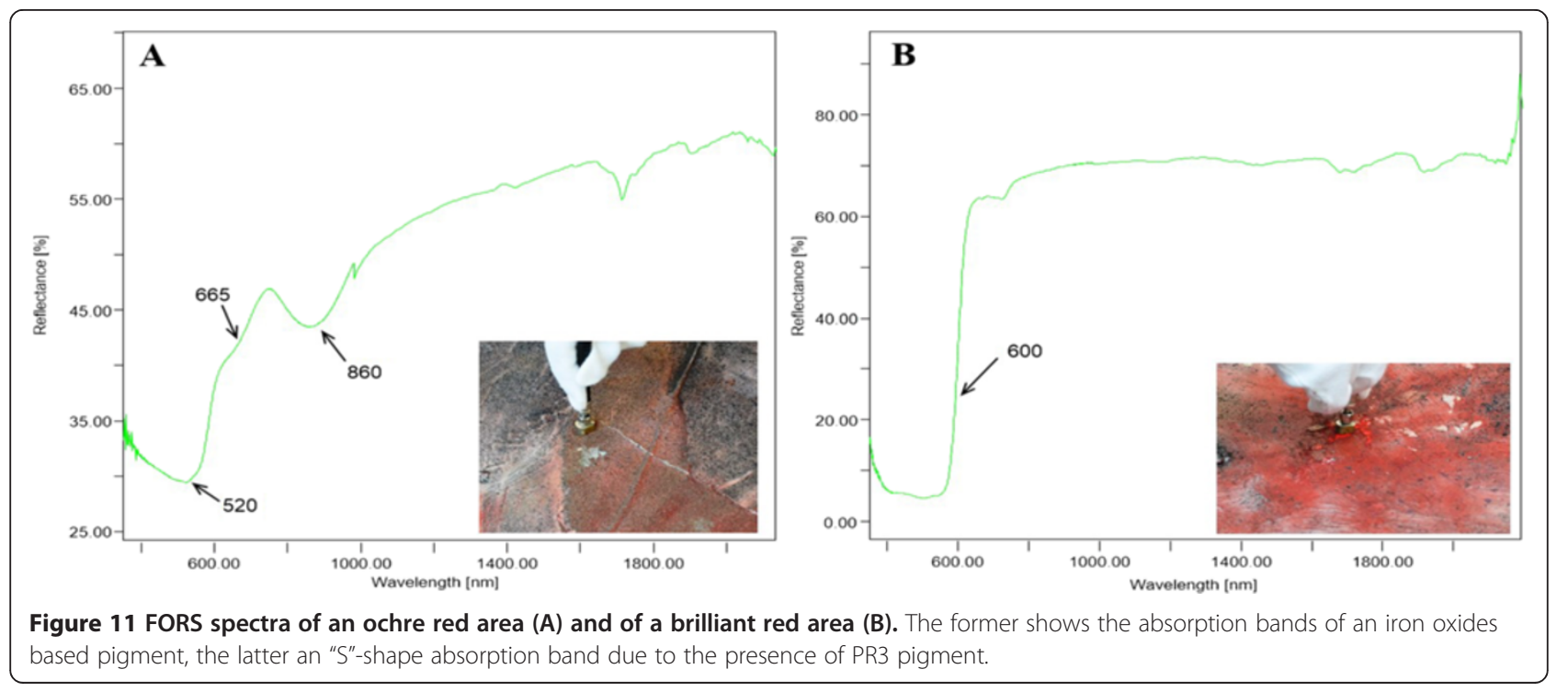




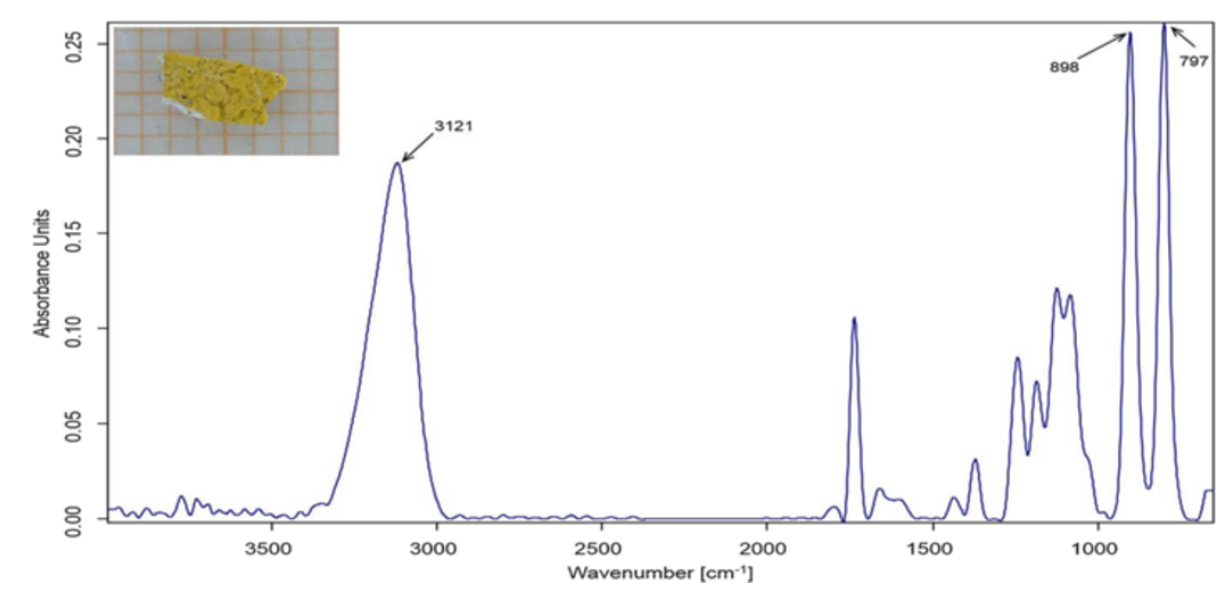

Figure 12 ATR FT-IR spectrum of sample A8 (inner surface). It shows the absorption bands of goethite.

Since preservation of the integrity of the object is a priority in the art conservation field, non-invasive and microinvasive analytical techniques were applied in order to identify the main compounds that constitute this work of art.

The integrated use of FORS, FT-IR and Raman spectroscopies was successfully employed to reconstruct the artist's pictorial palette, while Py-GC/MS and GC/MS made it possible to identify the binding media used by the artist (Table 2).
The results obtained enabled us to affirm that Gallizio in this work used traditional organic pigments, such as ultramarine blue, lithopone, and carbon black, as well as modern organic ones, such as monoazo PY3 yellow pigment, PR3 monoazo red pigment, and phthalocyanine blue PB15. Pigments were applied by the artist using a PVAc binder on the canvases of the ceiling, while siccative oils and PVAc were found on the canvas of the wall. Wires, sand and traces of gunpowder were also observed, thus confirming Gallizio's use of unconventional artists' materials.

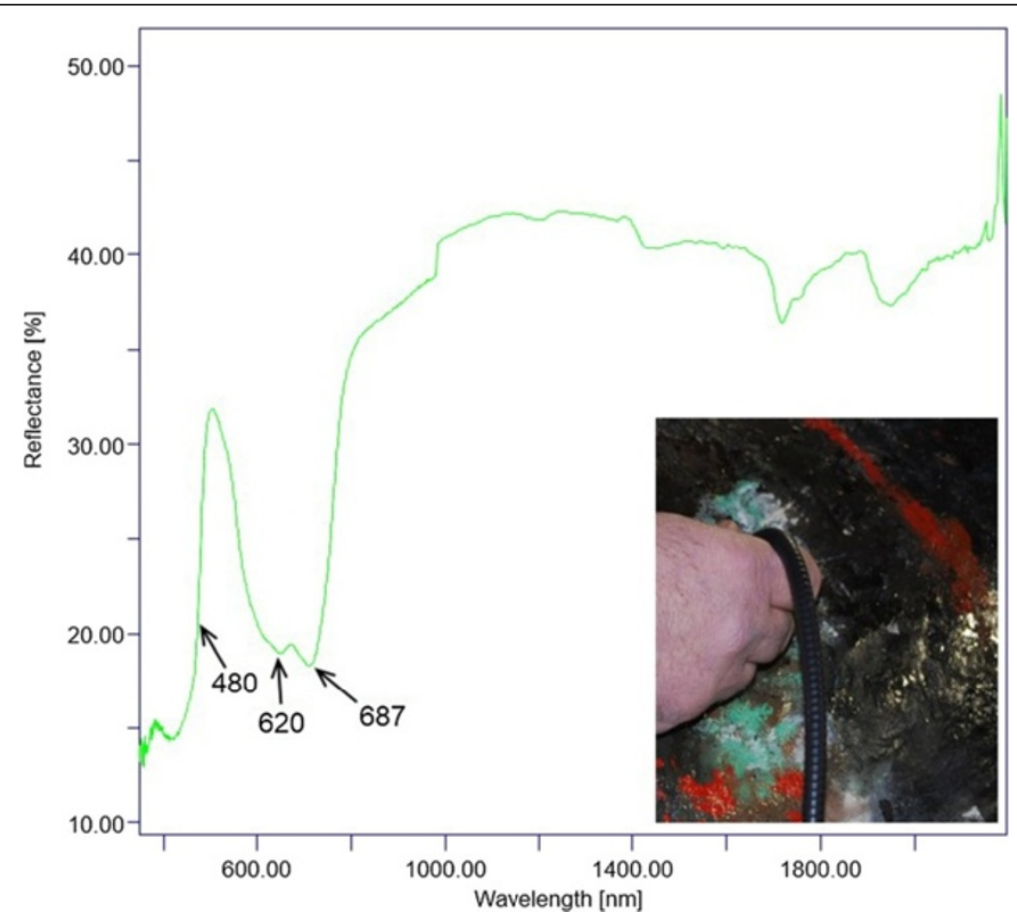

Figure 13 FORS spectrum of a green area. It shows the spectral features of a mixture of a phthalocyanine blue and a yellow pigment. 
Table 2 Summary of samples, analytical techniques and identified materials

\begin{tabular}{|c|c|c|c|}
\hline Sample & Colour & Analysis & Identified materials \\
\hline P1 & black & F1; IR2; R & $\begin{array}{l}\text { carbon based } \\
\text { pigment, calcite, } \\
\text { lithopone }\end{array}$ \\
\hline P2 & black/white & F1 & lithopone \\
\hline P3 & black/white & $\mathrm{F} 1 ; \mathrm{F} 2 ; \mathrm{IR} 2$ & lithopone \\
\hline P4 & blue & $F 1 ; R$ & $\begin{array}{l}\text { ultramarine blue, } \\
\text { calcite, lithopone }\end{array}$ \\
\hline P5 & pink/black & $\mathrm{F} 1 ; \mathrm{F} 2 ; \mathrm{IR} 1$ & iron oxides, lithopone \\
\hline P6 & yellow & $\mathrm{F} 1 ; \mathrm{IR} 2 ; \mathrm{R}$ & $\begin{array}{l}\text { monoazo PY3 yellow } \\
\text { pigment, calcite, } \\
\text { lithopone }\end{array}$ \\
\hline P7 & dark grey & F1 & lithopone \\
\hline P8 & blue/green & F1; IR2; R; PY & $\begin{array}{l}\text { ultramarine blue, } \\
\text { lithopone, PVAc }\end{array}$ \\
\hline P9 & yellow & $\mathrm{F} 1 ; \mathrm{F} 2 ; \mathrm{IR} 2$ & goethite, lithopone \\
\hline P10 & black/white & F1 & lithopone \\
\hline P11 & black/white & $\mathrm{F} 1 ; \mathrm{IR} 1 ; \mathrm{IR} 2$ & lithopone \\
\hline P12 & dark grey & - & $\begin{array}{l}\text { erratic sample, } \\
\text { probably not } \\
\text { belonging to the } \\
\text { stripe }\end{array}$ \\
\hline
\end{tabular}

$\begin{array}{lll}\text { P13 } & \text { white/blue } & \text { F1; IR1 } \\ \text { L1 } & \text { black } & \text { IR1 } \\ \text { L2 } & \text { white/green } & \text { F2; IR1; R } \\ \text { L3 } & \text { blue } & \text { F1; IR1; R; PY }\end{array}$

$\begin{array}{lll}\text { L4 } & \text { yellow } & \text { IR1; R } \\ \text { L5 } & \text { black } & \text { F1; IR1; R } \\ \text { L6 } & \text { white } & \text { F2; IR } 1 \\ \text { L7 } & \text { red } & \text { IR1; R } \\ \text { L8 } & \text { orange } & \text { IR } ; \text { R } \\ \text { L9 } & \text { dark red } & \text { F1; IR } 1 ; R \\ \text { L10 } & \text { blue } & \text { IR1; R; PY } \\ \text { L11 } & \text { white } & \text { IR } 1 \\ \text { L12 } & \text { green } & \text { IR1; R; PY }\end{array}$

$\begin{array}{lll}\text { L13 } & \text { blue } & \text { IR1; R } \\ \text { L14 } & \text { yellow } & \text { F1; IR1; R }\end{array}$

Table 2 Summary of samples, analytical techniques and identified materials (Continued)

\begin{tabular}{|c|c|c|c|}
\hline L15 & light green & $\mathrm{IR} 1 ; \mathrm{R}$ & phthalocyanine blue \\
\hline L16 & light brown & $\mathrm{F} 1 ; \mathrm{IR} 1 ; \mathrm{R}$ & PVAC \\
\hline L17 & resin & $\mathrm{IR} 1 ; \mathrm{R}$ & $\begin{array}{l}\text { PVAc, monoazo PY3 } \\
\text { yellow pigment, } \\
\text { phthalocyanine blue }\end{array}$ \\
\hline L18 & green & $\mathrm{IR} 1 ; \mathrm{R}$ & $\begin{array}{l}\text { barium sulphate, } \\
\text { monoazo PY3 yellow } \\
\text { pigment, } \\
\text { phthalocyanine blue }\end{array}$ \\
\hline $\mathrm{A} 1$ & pink/red & $\mathrm{F} 1 ; \mathrm{IR} 1 ; \mathrm{IR} 2 ; \mathrm{R}$ & $\begin{array}{l}\text { toluidine red, } \\
\text { lithopone, gypsum }\end{array}$ \\
\hline A2 & violet & IR1; R; PY & PVAc, lithopone \\
\hline A3 & blue & $\mathrm{F} 2 ; \mathrm{IR} 1$ & ultramarine blue \\
\hline A4 & green & IR1; IR2; R & $\begin{array}{l}\text { ultramarine blue, } \\
\text { gypsum, barium } \\
\text { sulphate }\end{array}$ \\
\hline A5 & white & $\mathrm{F} 1 ; \mathrm{F} 2 ; \mathrm{IR} 1 ; \mathrm{IR} 2 ; \mathrm{R}$ & $\begin{array}{l}\text { lithopone, carbon } \\
\text { based pigment }\end{array}$ \\
\hline A6 & blue & IR1; IR2 & $\begin{array}{l}\text { ultramarine blue, } \\
\text { barium sulphate }\end{array}$ \\
\hline A7 & violet & $\mathrm{F} 1 ; \mathrm{IR} 1 ; \mathrm{IR} 2 ; \mathrm{R}$ & $\begin{array}{l}\text { barium sulphate, } \\
\text { calcite }\end{array}$ \\
\hline A8 & yellow & IR1; IR2; R & goethite, lithopone \\
\hline A9 & black/white & $\mathrm{F} 2 ; \mathrm{IR} 1 ; \mathrm{IR} 2$ & lithopone \\
\hline A10 & white/pink & $\mathrm{F} 1 ; \mathrm{IR} 1 ; \mathrm{IR} 2 ; \mathrm{R}$ & lithopone \\
\hline A11 & pink & $\mathrm{F} 1 ; \mathrm{IR} 1 ; \mathrm{IR} 2$ & $\begin{array}{l}\text { lithopone, toluidine } \\
\text { red, calcite }\end{array}$ \\
\hline $\mathrm{A} 12$ & violet/yellow & $\mathrm{F} 1 ; \mathrm{IR} 1 ; \mathrm{IR} 2 ; \mathrm{R}$ & $\begin{array}{l}\text { goethite, barium } \\
\text { sulphate }\end{array}$ \\
\hline A13 & resin & $\mathrm{F} 1 ; \mid \mathrm{R} 1$ & PVAC \\
\hline A14 & red & IR1; IR2; R & toluidine red, calcite \\
\hline A15 & resin & $\mathrm{IR} 1 ; \mathrm{R}$ & PVAc, barium sulphate \\
\hline A16 & resin & $\mathrm{IR} 1$ & PVAc, barium sulphate \\
\hline A17 & black & $\mathrm{F} 1 ; \mathrm{IR} 1 ; \mathrm{R}$ & $\begin{array}{l}\text { toluidine red, } \\
\text { lithopone, goethite, } \\
\text { carbon based } \\
\text { pigment }\end{array}$ \\
\hline A18 & resin & IR1; IR2; R & $\begin{array}{l}\text { PVAc, barium } \\
\text { sulphate, calcite, }\end{array}$ \\
\hline A19 & white & F1; IR1; IR2; R; PY & PVAc, lithopone \\
\hline A20 & yellow/brown & $\mid \mathrm{R} 1$ & $\begin{array}{l}\text { PVAc, barium } \\
\text { sulphate, goethite }\end{array}$ \\
\hline
\end{tabular}

Legend - (F1: FORS (350-2200 nm); F2: FORS (270-800 nm); IR1: FT-IR ATR; IR2: FT-IR transmittance; R: Raman; PY: Py-GC/MS and GC/MS.

All of the collected results found in this study are now available to the curators of the "Luigi Pecci Center of Contemporary Art", and can be used to evaluate the conservation-state of the investigated artwork and to identify its risk factors in order to select the most appropriate preservation practices. 


\section{Competing interests}

The authors declare that they have no competing interests.

\section{Authors' contributions}

GB, CC, VM, SM and MP performed and interpreted the FT-IR and FORS analysis and drafted the paper EG, SL, GL, SP and VP acquired and interpreted the micro-Raman spectra and wrote the paragraphs in the manuscript concerning this technique FDG, JLN, FM and MPC performed and interpreted the Py-GC/MS and the GC/MS analysis and wrote the paragraphs in the manuscript concerning these techniques. All authors read and approved the final manuscript.

\section{Acknowledgements}

The authors wish to thank the Regione Toscana (Tuscany, Italy) for financing the Preventive Conservation of Contemporary Art (CoPAC, 2011-2013) Project within the framework of PAR-FAS Regional Project (2007-13). A special acknowledgement to Stefano Pezzato and Raffaele Di Vaia, curators of the "Luigi Pecci Center for Contemporary Art" (Prato, Italy), for having permitted us the access to the work of art.

Thanks also to the Archive Gallizio for providing useful information regarding the Gallizio's artistic technique.

\section{Author details}

"Nello Carrara" Institute of Applied Physics - National Research Council (IFAC-CNR), Via Madonna del Piano 10, Sesto Fiorentino, FI 59100, Italy. ${ }^{2}$ University of Florence, Piazza di San Marco, 4, Firenze 50121, Italy. ${ }^{3}$ Institute of Chemistry of Organometallic Compounds, Research Area of National Research Council, Via G. Moruzzi, 1-56124 Pisa, Italy. ${ }^{4}$ INSTM-SCIBEC, Dipartimento di Chimica e Chimica Industriale, Pisa Via Risorgimento 35, Pisa 56126, Italy.

Received: 1 July 2014 Accepted: 20 November 2014

Published online: 12 December 2014

\section{References}

1. Bertolino G, Comisso F, Roberto MT: Pinot Gallizio. Il laboratorio della scrittura. Milano: Charta eds; 2005.

2. Repetto M, Balla P: Dèrive Gallizio. Documentary Film, Written and Directed by Monica Repetto and Pietro Balla, Monica Repetto and Fondazione Ferrero Onlus Production. Italy: Deriva Film; 2000.

3. Roberto MT, Comisso F: Pinot Gallizio. Catalogo Generale Delle Opere 1953 1964. Milano: Gabriele Mazzotta eds; 2001.

4. Bonaduce I, Colombini MP, Degano I, Di Girolamo F, La Nasa J, Modugno F, Orsini S: Mass spectrometric techniques for characterizing low-molecularweight resins used as paint varnishes. Anal Bioanal Chem 2013, 405:1047-1065.

5. Renuka Devi KB, Madivanane R: Normal coordinate analysis of poly vinyl acetate. IRACST-Eng Sci Technol 2012, 2(4):795-799.

6. Carbò MTD, Bitossi G, Osete-Cortina L, de la Cruz-Canizares J, Yusà-Marco DJ: Characterization of polyvinyl resins used as binding media in paintings by pyrolysis-silylation -gas chromatography-mass spectrometry. Anal Bioanal Chem 2008, 391:1371-1379.

7. Colombini MP, Andreotti A, Bonaduce I, Modugno F, Ribechini E: Analytical strategies for characterizing organic paint media using Gas chromatography/mass spectrometry. Acc Chem Res 2010, 43(6):715-727.

8. Bertolino G, Comisso F, Dematteis L, Roberto MT: Pinot Gallizio: I'uomo, l'artista e la città (1902-1964). Milano: Mazzotta; 2000.

9. Ramaswamy V, Vimalathithan RM, Ponnusamy V: Synthesis of well dispersed, elliptical shaped Barium Sulphate nanoparticles via Water-Chloroform mixed solvent. Arch Phys Res 2010, 1(4):217-226.

10. Weakleim $\mathrm{H}$ : Optical spectra of $\mathrm{Ni}^{2+}, \mathrm{Co}^{2+}$, and $\mathrm{Cu}^{2+}$ in tetrahedral sites in crystals. J Chem Phys 1962, 36:2117-2140.

11. Van Alphen M: Paint Film Components, Monograph, general series 2. Australia: National Environmental Health Forum; 1998.

12. Picollo M, Bacci M, Magrini D, Radicati B, Trumpy G, Tsukada M, Kunzelman D: Modern White Pigments: Their Identification by Means of non Invasive Ultraviolet, Visible and Infrared Fiber Optic Reflectance Spectroscopy. In Modern Paints Uncovered: Proceedings From the Modern Paints Uncovered Symposium, (May 16-19, 2006, Tate Modern, London). Edited by Learner TJS, Patricia S, Krueger JW, Schilling MR. Los Angeles: Getty Conservation Institute Symposium Proceedings Series. Getty Conservation Institute; 2007:129-139.
13. Jehlička J, Vítek P, Edwards HGM, Hargreaves MD, Capoun T: Fast detection of sulphate minerals (gypsum, anglesite, barite) by a portable Raman spectrometer. J Raman Spectrosc 2009, 40:1082-1086.

14. Burgio L, Clark RJH: Library of FT-Raman spectra of pigments, minerals, pigment media and varnishes, and supplement to existing library of Raman spectra of pigments with visible excitation. Spectrochim Acta Part A 2001, 57:1491-1521.

15. Bell IM, Clark RJH, Gibbs PJ: Raman spectroscopic library of natural and synthetic pigments (pre- $\approx 1850$ AD). Spectrochim Acta Part A 1997, 53:2159-2179.

16. Bruni S, Cariati F, Casadio F, Toniolo L: Spectrochemical characterization by micro-FTIR spectroscopy of blue pigments in different polychrome works of art. Vib Spectrosc 1999, 20(1):15-25.

17. Learner TJS: Analysis of Modern Paints. Los Angeles: Getty Conservation Institute; 2004

18. Vahur S, Teearu A, Leito I: ATR-FT-IR spectroscopy in the region of $550-230 \mathrm{~cm}^{-1}$ for identification of inorganic pigments. Spectrochim Acta Part A 2010, 5(3):1061-1072.

19. Clark RJH, Franks ML: The resonance Raman spectrum of ultramarine blue. Chem Phys Lett 1975, 34:69-72.

20. Osticioli I, Mendesa NFC, Nevinc A, Gil FPSC, Becucci M, Castellucci E: Analysis of natural and artificial ultramarine blue pigments using laser induced breakdown and pulsed Raman spectroscopy, statistical analysis and light microscopy. Spectrochim Acta Part A 2009, 73:525-531.

21. Herbst W, Hunger K: Industrial Inorganic Pigments. Production, Properties, Applications, New York. Weinheim: Gunter Buxbaum; 1993.

22. Bacci M: UV-VIS-NIR, FT-IR and FORS Spectroscopies. In Modern Analytical Methods in Art and Archaeology, Chemical Analysis Series, Vol.155, Chapter 12. Edited by Ciliberto E, Spoto G. USA: John Wiley \& Sons, Inc; 2000:321-361.

23. Scherrer NC, Zumbuehl S, Delavy F, Fritsch A, Kuehnen R: Synthetic organic pigments of the 20th and 21st century relevant $t$ artist's paints: Raman spectra reference collection. Spectrochim Acta Part A 2009, 73(3):505-524

24. Vandenabeele P, Moens L, Edwards HGM, Dams R: Raman spectroscopic database of azo pigments and application to modern art studies. J Raman Spectrosc 2000, 31(6):509-517.

25. Lake S, Lomax SQ: Arylide (Hansa) Yellow Pigments. In Artists' Pigments. A Handbook of Their History and Characteristics, Vol. 4. Edited by Berrie BH. London: Archetype publications; 2007:179-222.

26. Sherman DM, Waite TD: Electronic spectra of Fe(III) oxides and oxides hydroxides in the near IR to near UV. Am Mineral 1985, 70:1262-1269.

27. Cornell RM, Schwertmann U: The Iron Oxides Structure, Properties, Reactions, Occurrence and Uses, VCH. Weinheim: Verlagsgesellschaft; 1996.

28. Afremow LC, Vanderberg JT: High resolution spectra of inorganic pigments and extenders in the mid-infrared region from $1500 \mathrm{~cm}^{-1}$ to $200 \mathrm{~cm}^{-1}$. J Paint Technol 1966, 38:169-202.

29. Cambier $P$ : Infrared study of goethite of varying cristallinity ad particle size. I. Interpretation of $\mathrm{OH}$ and lattice vibration frequencies. Clay Miner 1986, 21:191-200.

30. Johnston RM: Spectrophotometry for the analysis and description of color. J Paint Technol 1967, 39:346-354.

31. Johnston RM, Feller RL: The use of differential spectral curve analysis in the study of museum objects. Dyestuffs 1963, 44:1-10.

\section{doi:10.1186/s40494-014-0029-7}

Cite this article as: Bartolozzi et al:: A multidisciplinary approach to the investigation of "La Caverna dell'Antimateria" (1958-1959) by Pinot Gallizio. Heritage Science 2014 2:29. 